\title{
Structual Peculiarities of Exopolysaccharides of Phototrophic Bacteria Rhodobacter sphaeroides
}

\author{
L. S. Markosyan ${ }^{1, *}$, R. S. Oganesyan ${ }^{1}$, I. E. Melkumyan ${ }^{1}$, S. S. Mamyan ${ }^{2}$ \\ ${ }^{1}$ Institute of Microbiology, SPC Armbiotechnology NAS of Armenia \\ ${ }^{2}$ Molecular Structure Research Centre, NAS of Armenia \\ *Corresponding Author: lmark@sci.am
}

Copyright (C) 2014 Horizon Research Publishing All rights reserved.

\begin{abstract}
For the first time, properties and structural peculiarities of exopolysaccharides produced by phototrophic bacteria Rhodobacter sphaeroides isolated from hydrocarbonate mineral waters in Armenia with a degree of mineralization in limits of $3.5-5.0 \mathrm{~g} / \mathrm{l}, \mathrm{pH} 7.2$ have been studied. It is noteworthy that despite membership of the isolated strains in one and the same genus, these strains are significantly different by the nature of the produced exooligosaccharide. The studies implemented show that phototrophic bacteria are able to synthesize exopolysaccharides with different compositions and structures: cyclic and linear, depending on the cultivation conditions.
\end{abstract}

Keywords Exopolysaccharide, NMR Spectrum, Phototrophic Bacteria

\section{Introduction}

Microorganisms belonging to various Genera and producing exopolysaccharides have been described [1-6]. The microbial polysaccharides are very important for cells in population, in the process of adhesion and also in protection of cells [7-11]. Many microbial polysaccharides are used in food production, pharmaceutical, cosmetic, textile industries and other fields. The structure and function of polysaccharides producing by different microorganisms have been studied [12-19].

Phototrophic microorganisms represent considerable interest for productions various biologically active compounds - vitamins, carotenoids, organic acids, enzymes, etc. However, the biosynthesis and properties of polysaccharides produced by phototrophic bacteria are not entirely studied and represent prospective areas of study.

The aim of these researches is to study the properties and structural peculiarities of exopolysaccharides produced by the strains of phototrophic bacteria Rhodobacter sphaeroides.

\section{Materials and Methods}

Strains and media. Phototrophic bacteria Rhodobacter sphaeroides, designated as A-1 and D-1 have been isolated from hydrocarbonate water sources of Armenia (Arzni and Jermuk) with a degree of mineralization of 3.5-5.0 g/l, pH 7.2. The strain of $R h$. sphaeroides A1 was cultivated in the under stationary conditions with illumination intensity of 2500-3000 lux, at $30^{\circ} \mathrm{C}$, during 8 days in slightly modified Ormerod's nutrition medium [20]: (g/l) $\mathrm{KH}_{2} \mathrm{PO}_{4}-0.6$, $\mathrm{K}_{2} \mathrm{HPO}_{4}-0.9,\left(\mathrm{NH}_{4}\right)_{2} \mathrm{SO}_{4}-0.5, \mathrm{MgSO}_{4} \cdot 7 \mathrm{H}_{2} \mathrm{O}-0.2, \mathrm{CaCl}_{2}$ $2 \mathrm{H}_{2} \mathrm{O}-0.08, \mathrm{FeSO}_{4} \cdot 7 \mathrm{H}_{2} \mathrm{O}-0.012$, Na-acetate -7.0 ,or succinat, biotin $-15 \mathrm{mg}$, microelements $-1 \mathrm{ml}, \mathrm{pH}-7.0$.

The total quantity of sugars was determined by anthrone method [21].

Antimicrobial activity of polysaccharides was identified by the agar diffusion methods [22].

NMR spectra were registered on spectrometer MERCURY 300Vx (Varian) with resonance frequency of 300.077 and $75.465 \mathrm{MHz}$, on ${ }^{1} \mathrm{H}$ and ${ }^{13} \mathrm{C}$ nuclei, respectively. Heavy water was used as solvent. In the NMR spectrum, ${ }^{13} \mathrm{C}$ signal of methanol group $\left(\delta\left(\mathrm{CH}_{3}\right) 49 \mathrm{ppm}\right)$ acted as the internal standard.

Isolation of exopolysaccharids was carried out according to the following method developed by as (diagram).

\footnotetext{
Diagram. Isolation of Oligosaccharide
Cultivation of strains of $R \mathrm{~h}$. sphaeroides in Ormerod's medium under anaerobic conditions $\left(30^{\circ} \mathrm{C}, 2500 \mathrm{lux}, 150\right.$ hours).

Removal of cells from the culture liquid by centrifugation $(15000 \mathrm{~g} / 20 \mathrm{~min})$ after fivefold dilution with water.

Decoloration of the culture liquid by activated carbon $\left(2\right.$ hours at $\left.50-60^{\circ} \mathrm{C}\right)$, filtration. $\downarrow$

Concentration of the clarified filtrate at $40-45^{\circ} \mathrm{C}$ to $30 \%$ of the initial volume. $\downarrow$

Precipitation of exopolysaccharides by ethanol (1:3w/w). $\downarrow$

Purification of exopolysaccharide by gel filtration on Sephadex G-25; G-50 and ToyoPerl 650M. $\downarrow$ lyophilisation
} 


\section{Results and Discussion}

Studies of morpho-physiological and biochemical characteristics of Rh. sphaeroides strains A-1, D-1 have revealed that they are Gram-positive and can grow in nutrient medium containing organic substrates under anaerobic conditions in the light, as well as under aerobic conditions in the dark. Electron microscopic studies have shown that the cells of the studied bacteria are of sphaerical form (2.0 - 2.5 to 1.3-1 mc) (Figure 1).



A

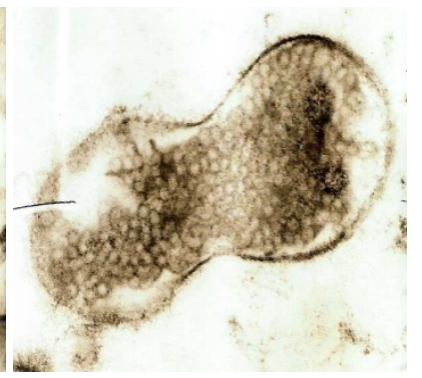

B
Figure 1. Electron microphotography of $R h$. sphaeroides A-1 (A) and division (B), (x15600)

The mentioned cultures grew well in the cultivation medium, containing the salts of organic acids - acetate, piruvate, lactate, malate, fumarate, succinate as well as glucose, fructose, maltose, saccharose and other sugars. Microscopic studies have shown that bacterial cells form a mucous capsule.

Studies of synthesis of exopolysaccharides have demonstrated that their content reaches maximum in the 6-7 days of cultivation, which coincides with the maximum of culture growth. Under further cultivation the level of sugars is not changed, as the case with the biomass (Figure 2).

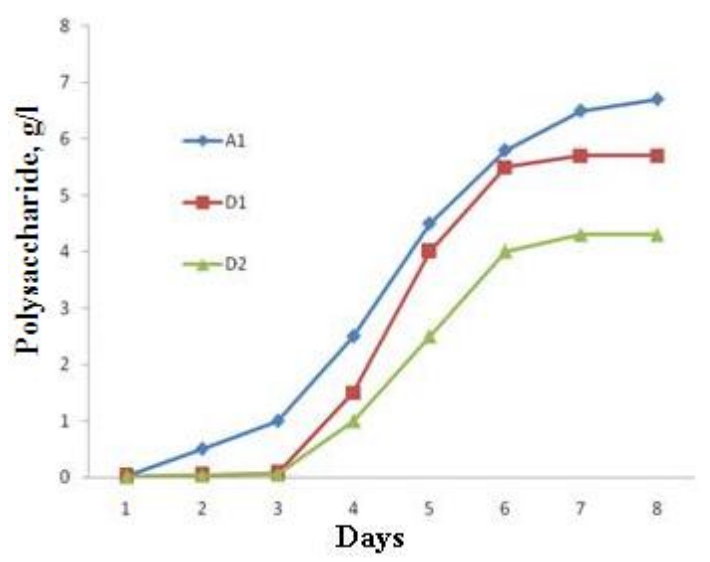

Figure 2. Synthesis of exopolysaccharids by Rh. sphaeroides (A1, D1 in the medium with acetate and D2- with succinate)

Microbial polysaccharides are known to be biologically active[ $2,11,18,22]$.. Our studies of the effect of the isolated exopolysaccharides on microorganisms- E. coli, B. subtilis, Candida albicans - have not indicate any antimicrobial activity.
Structural peculiarities of the noted exopolysaccharide have been studied by means of nuclear-magnetic resonance (NMR) spectroscopy of hydrogen and carbon atom nuclei. The ${ }^{13} \mathrm{C}$ NMR spectrum of the exopolysaccharide from $R h$. sphaeroides strain A-1 contains six absorption signals from six non-equivalent carbon atoms (Figure 3).

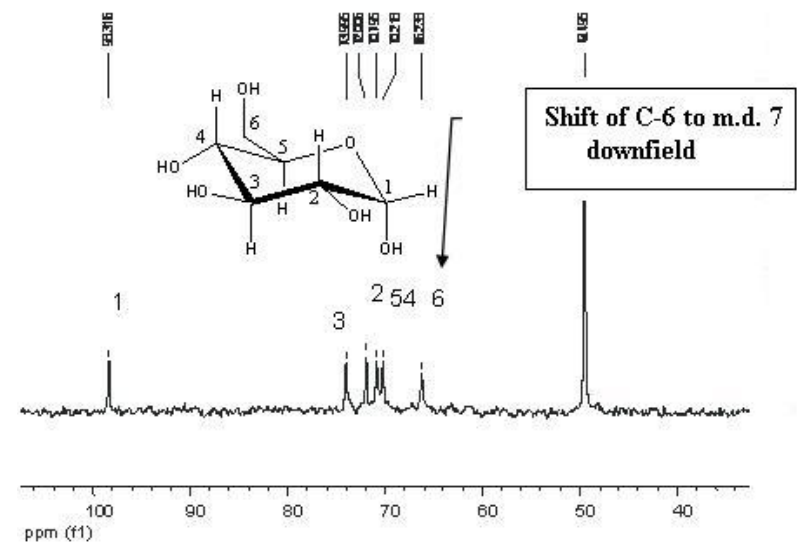

Figure 3. ${ }^{13} \mathrm{C}$ NMR spectrum of exopolysacharide of $R h$. sphaeroides A-1

The J-coupling values for proton NMR of polysaccharide of Rh. sphaeroides A-1 are: $\delta\left(\mathrm{C}_{1}\right) 98.3 \mathrm{ppm}, \delta\left(\mathrm{C}_{2}\right) 72.0 \mathrm{ppm}$, $\delta\left(\mathrm{C}_{3}\right) 74.01 \mathrm{ppm}, \delta\left(\mathrm{C}_{4}\right) 70.22 \mathrm{ppm}, \delta\left(\mathrm{C}_{5}\right) 70.80 \mathrm{ppm}, \delta\left(\mathrm{C}_{6}\right)$ $66.24 \mathrm{ppm}$.

The comparison of the abovementioned spectrum with ${ }^{13} \mathrm{C}$ NMR spectrum of $\alpha$-glucose has revealed good coincidence of signals chemical shifts for carbon atoms in positions $2-5$, whereas carbon atom signals in positions 1 and 6 were significantly different. This indicates that $\alpha$-glucose is the base of the oligosaccharide, and glycosidic residues are connected in positions $\mathrm{C} 1$ and C6 (Figure 4).

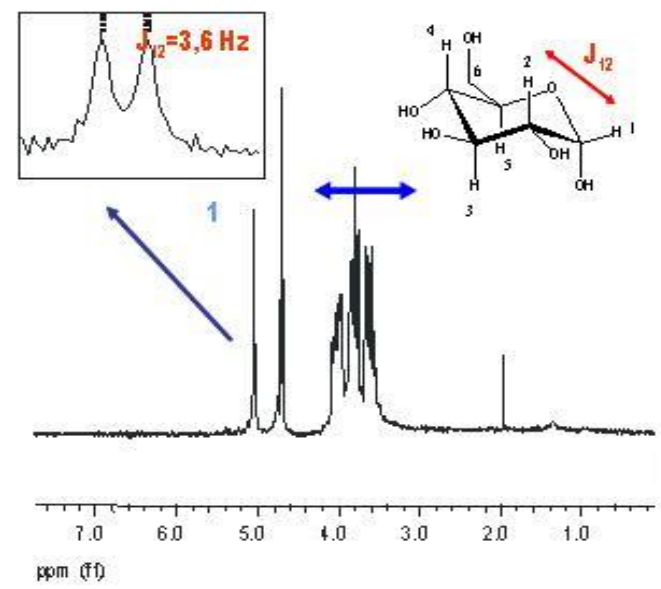

Figure 4. ${ }^{1} \mathrm{H}$ NMR spectrum of the exopolysaccharide of Rh.sphaeroides A-1

Analysis of the proton spectra of the oligosaccharide in question agrees well with the abovementioned (Figure 5 and Table 1).

The doublet signal of anomeric hydrogen atom with the spin-spin interaction constant $\mathrm{J}=3.6 \mathrm{~Hz}$ indicate the evidences of $\alpha$-configuration of the monosaccharide. 
Secondly, detailed analysis of multiplet structure and determination of the spin-spin interaction constant between nuclei 1 and 2, 2 and 3,3 and 4, 4 and 5 indicates that $\alpha$-glucose is the monosaccharide residue. and 7 molecules are connected in positions $\mathrm{C} 1$ and $\mathrm{C} 6$, forming a cyclic structure with certain elements of symmetry and molecular mass 1135 (Figure 6).

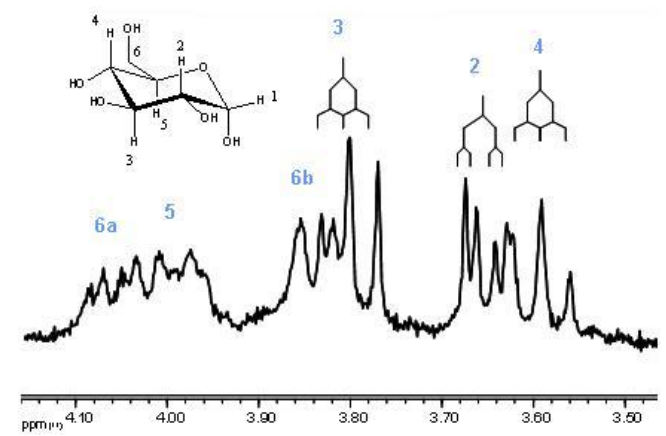

Figure 5. ${ }^{1} \mathrm{H}$ NMR spectrum of the exopolysaccharide of Rh. sphaeroides A-1, proton regions 2-6

Table 1. NMR ${ }^{1} \mathrm{H}$ spectrum for polysaccharide of Rh. sphaeroides A-1

\begin{tabular}{|c|c|c|c|}
\hline Proton & $\delta p p m$ & Multiplate & $\mathrm{J}$ \\
\hline $\mathrm{H}_{1}$ & 5.05 & $\mathrm{~d}$ & $\mathrm{~J}_{1.2} 3.6$ \\
\hline $\mathrm{H}_{2}$ & 3.65 & $\mathrm{dd}$ & $\mathrm{J}_{1.2} 3.6, \mathrm{~J}_{2.3} 9.8$ \\
\hline $\mathrm{H}_{3}$ & 3.80 & $\mathrm{t}$ & $\mathrm{J}_{2.3} 9.7, \mathrm{~J}_{3.4} 9.8$ \\
\hline $\mathrm{H}_{4}$ & 3.59 & $\mathrm{t}$ & $\mathrm{J}_{3.4} 9.2, \mathrm{~J}_{4.5} 9.8$ \\
\hline $\mathrm{H}_{5}$ & 3.99 & $\mathrm{~m}$ & \\
\hline $\mathrm{H}_{6 \mathrm{a}}$ & 4.06 & $\mathrm{~m}$ & \\
\hline $\mathrm{H}_{6 \mathrm{~b}}$ & 3.84 & $\mathrm{~m}$ & \\
\hline
\end{tabular}

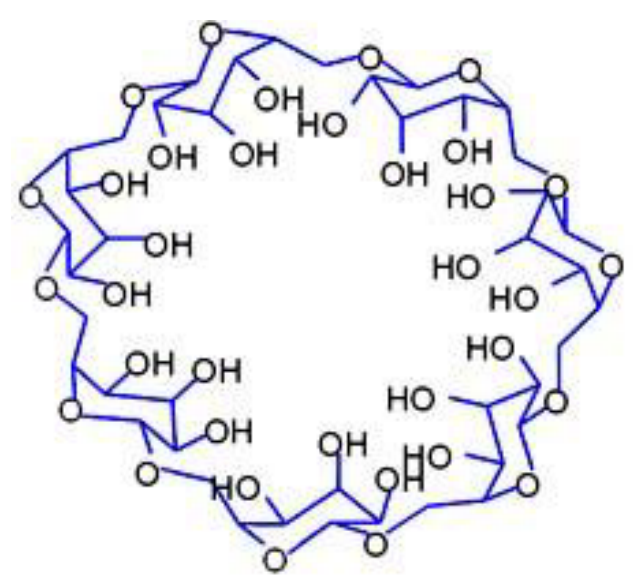

Figure 6. Cyclic structure of the 1,6 oligosaccharide of Rh. sphaeroides A-1

It is important to note that spectra of oligosaccharide with linear structure and, therefore, without symmetry elements, would have appeared to be much more complex than the observed spectra. In particular, the ${ }^{13} \mathrm{C}$ NMR spectrum of such oligosaccharide should have consisted of several tens of signals.

The influence of different sources of carbon on the peculiarity of exopolysaccharide produced by $R h$. sphaeroides D-1 has been carried out. Investigations of ${ }^{13} \mathrm{C}$ NMR spectrum of exopolysaccharide of phototrophic bacteria $R h$. sphaeroides D-1 grown in acetate containing medium as the only source of carbon reveled the presence of numerous different intensity signals (Figure 7).

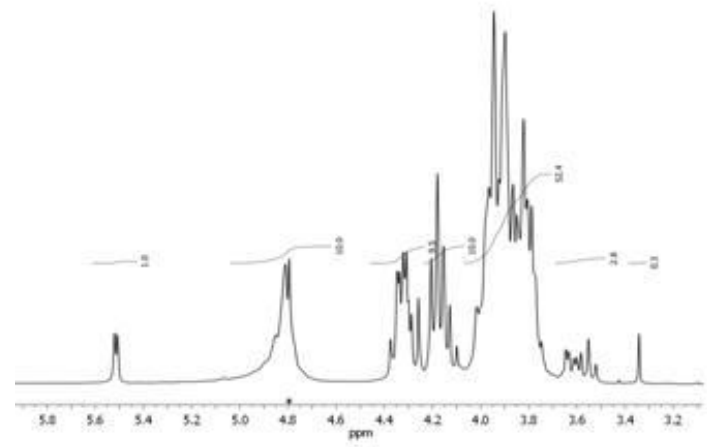

Figure 7. ${ }^{13} \mathrm{C}$ NMR spectrum of the polysaccharide Rh. sphaeroides D-1 grown on accetate medium

The results obtained indicate that the investigating polysaccharide consists of two different monomers of glucose and galactose. The same results have been obtained by proton NMR spectrum. It should also be mentioned that the exopolysaccharide of Rh.sphaeroides D-1 is a linear heteropolysaccharide.

In literature, it is assumed that the monomeric composition and structure of synthesized polysaccharide by microorganisms depend on the cultivation conditions, particularly from source of carbon $[7,12,14]$.

In order to study the possibility of changing the monomer composition and structure of exopolysaccharide of phototrophic bacteria of Rh. sphaeroides D-1, the cultivation has been carried out on Ormerud medium with succinate as the only source of carbon, instead of acetate. The studies of structural properties of isolated exopolysaccharide by ${ }^{13} \mathrm{C}$ NMR spectrum have shown the presence of six identical carbon signals which have proved that the polysaccharide is composed of identical monomers (Figure 8).



Figure 8. ${ }^{13} \mathrm{C}$ NMR spectrum of the polysaccharide Rh.sphaeroides D-1 grown on succinate medium 
In the proton NMR spectrum of investigated polysaccharide is observed $5.06 \mathrm{~mm}$ doublet swallowing with constant spin-spin interacts $3.8 \mathrm{~Hz}$, indicating that the polysaccharide is a part of the monomer $\alpha$-glucopyranoside (Figure 9).

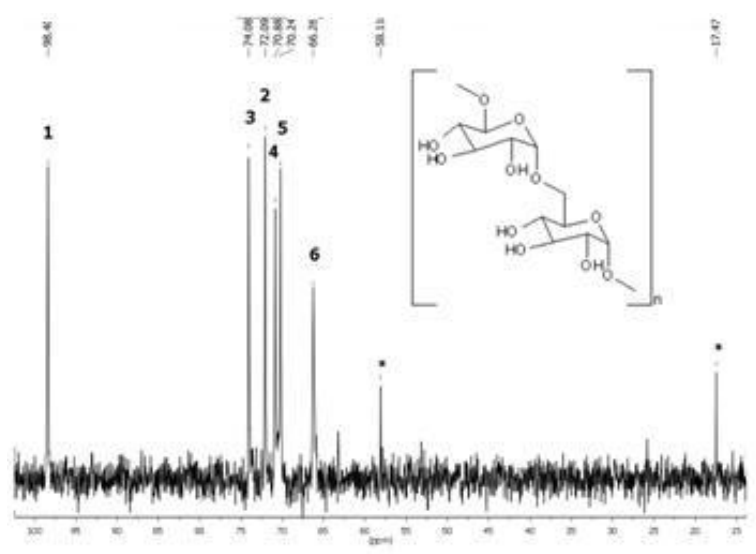

Figure 9. Proton NMR spectrum of the exopolysaccharide $R h$. sphaeroides D-1 grown in succinate medium

Simultaneously, the chemical deviation of C6 atom in the weak magnetic field direction of $5.0 \mathrm{~mm}$ indicates that monosaccharide residues have been connected by $\mathrm{C} 1-\mathrm{C} 6$ links. The presence of weak signal in proton-5.2mm spectrum of polysaccharide shows a linear nature of polymer. Thus, it has been revealed that in exopolysaccharide of $R h$. sphaeroides D-1 cultivated in the succinate medium as the only source of carbon the repeating unit of the polymer is 6) $\alpha$ - D - Glup - (1 - 6) - $\alpha$ - D-Glup (1.

\section{Conclusion}

Strains of phototrophic bacteria have been isolated from mineral hydro carbonic water (Armenia). The studies of morphological, physiological and biological properties allowed identifying them as strains of Rhodobacter sphaeroides. The isolated bacteria are gram positive and can utilize organic substrates: acetate, piruvate, lactate, fumarate, succinate as well as glucose, fructose, maltose, saccharose and other sugars as in anaerobic condition in the light and in aerobic conditions in the dark.

For the first time it has been shown that the phototrophic bacteria (Rh. spaeroides A1, D1) produce exopolysaccharides and it is noteworthy that in despite that isolated bacteria belonging the same genera can produced exopolysaccharides significantly differ by the structure and composition: in our study thr cyclic and linear forms have been described.

\section{REFERENCES}

[1] SutherlandL.W.. Microbial polysaccharides from Gram-negative bacteria. Int. Dairy J. Vol.11, 663-674, 2001.

[2] Kenne L., Lindberg B.. The polysaccharides. Academic Press, Vol.5, 287-363, 1983.

[3] Micheli L., Uccelletti D., Palleschi D.C., Crescenzi V., Isolation and characterisation of a ropy Lactobacillus strain producing the exopolysaccharide kefiran. Appl. Environ. Microbiol. Vol.53, 69-74, 1999.

[4] Naessens M,. Cerdobbel A., Soetaert W., Vandamme E.J.,. Leuconostoc dextransucrase and dextran: production, properties and applications. J. Chem. Technol. Biotechnol., Vol.80, 845-860, 2005.

[5] Vu Barbara, Miao Chen, Russell J.,Crawford L. and Elena Ivanova. Bacterial Extracellular Polysaccharides Involved in Biofilm Formation. Molecules, Vol.14, 2535-2554, 2009.

[6] Sutherland L.W.. Novel and established applications of microbial polysaccharides. Trends Biotechnol. Vol.16, 41-46, 1998.

[7] Rehm B.. Microbial exopolysaccharides: Variety and potential applications. In Microbia production of biopolymers and polymer precursors: applications and perspectives; CaisterAcademic: Norfolk, UK, 229-254, 2009.

[8] Pogliani C. and DonatiE. The role of exopolymers in the bioleaching of a non-ferrous metal sulphide. Journal of Industrial Microbiology \& Biotechnology Vol.22, 88-92, 1999.

[9] Vuong C., Kocianova S., J.M. Voyich J.M., Y. Yao, Fischer E.R., DeLeo F.R., Otto M.A.. Crucial role for exopolysaccharide modification in bacterial biofilm formation, immune evasion, and virulence. J. Biol. Chem. Vol.279, 54881-54886, 2004.

[10] Ertesvåg H., Valla S. Biosynthesis and applications of alginates. Polym. Degrad. Stab. Vol.59, 85-91,1998.

[11] Yang Z.. Antimicrobial compounds and extracellular Polysaccarides produced by lactic acid bacteria: structures and properties. Department of Food Technology, University of Helsinki, Academic Dissertation, 2000.

[12] Perpelov A.V. Senchenkova S.N., Shashkov A.S., Yu.A. Knirel, B. Lu, L. Feng, and L.Wang. Structures of O-polysaccharides from two type Shingella dysenteriae type 8 strains. Bioorganic Chemistry, Vol.34, No.6, 808-813, 2008

[13] Shashkov A.S., Yu.A. Knirel, Kocharova N.A., Dmitriev B.A., Kochetkov N.K.. ${ }^{13} \mathrm{C}$ NMR spectrum of Pseudomonas aeruginosa 7a, b specific polysaccharide. Bioorganic Chemistry, Vol.6, No.9, 1332-1337, 1980.

[14] Sanford P.A., Cottrell L.W., Pettitt P.J.. Microbial polysaccharides: New products and their commercial applications. Pure Appl. Chem Vol.56, 879-892, 1984.

[15] Flemming H.C., Wingender J.. Relevance of microbial extracellular polymeric substances (EPSs) - Part I: Structural and ecological aspects. Water Sci. Technol. Vol.43, 1-8. 2001 a.

[16] Duboc P., Mollet B. Applications of exopolysaccharides in the dairy industry. Int. Dairy J., Vol.11, 759-768, 2001.

[17] Jonas R., L.F. Farah L.F. Production and application of 
microbial cellulose. Polym. Degrad. Stab. Vol.59, 101-106, 1998.

[18] Dumitriu S.. Microbial exopolysaccharides. In Polysaccharides: Structural diversity and functional versatility; CRC Press: Marcel Dekker, New York, NY, USA, 431-457, 2004.

[19] Shashkov A.S., Knirel Yn.A., Kocharova N.A., Dmitriev B.A., Kochetkov N.K. 13C NMR spectrum of pseudomonas aeroginosa O-serotype 7a, b specific polysaccharide. Bioorg. Khim., 6(9), 1332-1337, 1980.

[20] J.G.,Ormerod.,K.S. Ormerod ,H. Gest . Light -dependent utilization of organic compounds and photoproduction of molecular hydrogen by phototrophic backteria; relationships with nitrogen metabolism. Arch. Biochem. Biophis. 94, 2, 449-463, 1961.

[21] Yemm E.W., Willis A.J.. The estimation of carbohydretes in plant extractions by antron. Biochem. J., 57, 3, 506-515, 1954.

[22] Cleidson Valgas1; Simone Machado de Souza; Elza F A Smânia; Artur Smânia Jr. Screening methods to determine antibacterial activity of natural products. Brazilian Journal of Microbiology (2007) 38:369-380. 